\title{
Basic mechanisms of urgency: roles and benefits of pharmacotherapy
}

\author{
Martin Christian Michel · Christopher R. Chapple
}

Received: 19 May 2009/Accepted: 19 June 2009/Published online: 9 July 2009

(c) The Author(s) 2009. This article is published with open access at Springerlink.com

\begin{abstract}
Introduction Since urgency is key to the overactive bladder syndrome, we have reviewed the mechanisms underlying how bladder filling and urgency are sensed, what causes urgency and how this relates to medical therapy.

Materials and methods Review of published literature.

Results As urgency can only be assessed in cognitively intact humans, mechanistic studies of urgency often rely on proxy or surrogate parameters, such as detrusor overactivity, but these may not necessarily be reliable. There is an increasing evidence base to suggest that the sensation of 'urgency' differs from the normal physiological urge to void upon bladder filling. While the relative roles of alterations in afferent processes, central nervous processing, efferent mechanisms and in intrinsic bladder smooth muscle function remain unclear, and not necessarily mutually exclusive, several lines of evidence support an important role for the latter.

Conclusions A better understanding of urgency and its causes may help to develop more effective treatments for voiding dysfunction.
\end{abstract}

Keywords Urgency - Urge to void - Bladder sensation

M. C. Michel $(\square)$

Department of Pharmacology and Pharmacotherapy,

Academic Medical Center, Meibergdreef 15,

1105 AZ Amsterdam, The Netherlands

e-mail: m.c.michel@amc.nl

\section{R. Chapple}

Department of Urology, Royal Hallamshire Hospital,

Sheffield Teaching Hospitals NHS Foundation Trust,

Sheffield S10 2JF, UK

\section{Introduction}

Urgency is the key symptom of the overactive bladder syndrome $(\mathrm{OAB})$ and is defined as the complaint of a sudden compelling desire to pass urine, which is difficult to defer' [1]. A better understanding of the genesis of urgency and its relationship to other aspects of bladder function is required to unravel the pathophysiology of $\mathrm{OAB}$ and to develop more effective treatments. An extended version of the thoughts discussed in this manuscript has been published elsewhere [2].

\section{Implications of the use of surrogate parameters for urgency}

The definition of urgency as a desire implies that it can only be measured in cognitively intact human beings. As a sensation it can be affected by neurological disorders and may, therefore, be perceived differently in patients with neurological lesions. Patient-activated keypad devices [3] or an 'urgeometer' [4] have been proposed as tools to capture the sensation of urgency in an objective fashion, but until now they have not been widely used. By contrast, mechanistic studies on urgency have employed the use of isolated tissues and experimental animals. As neither allows assessing a desire, they rely on surrogate markers such as non-voiding detrusor contractions (NVDCs). Several studies have explored the relationship between urgency and detrusor overactivity (DO). Only about half of all patients with DO experience urgency [5], whereas among patients with urgency 44-69\% exhibit DO during pressure-flow studies [6-9]. The correlation of urgency with DO is higher in males than in females, and in incontinent compared with continent patients. Possibly 
urgency in the absence of DO is not a separate entity, but rather part of a spectrum of bladder dysfunction [10]. Finally, abnormal filling sensations can be reported during fake cystometry [11]. Despite these limitations, NVDCs remain the most frequently used surrogate parameter to study mechanisms related to urgency in experimental animals. Other studies have linked specific mechanisms to the frequency of detrusor contractions or the number of incontinence episodes, rather than the occurrence of urgency. However, not all detrusor contractions are well captured by standard pressure-flow studies.

Two other factors are pivotal to the understanding of urgency. Firstly, as urgency is always a pathological sensation, it does not necessarily involve the same mechanisms as those occurring in response to physiological bladder filling. This limits the extrapolation from findings in animals or healthy individuals to those with urgency. Secondly, the ease with which the term urgency is used in English belies the lack of clarity relating to this distinction from normality in most other languages. The implications of all of these issues need to be considered in the interpretation of the subsequently presented data.

\section{Differential sensing of bladder filling and urgency}

Physiological filling signals from the bladder are conveyed to the spinal cord by the pelvic, hypogastric and pudendal nerves. They comprise thin, but myelinated, $\mathrm{A} \delta$-fibres and even thinner and non-myelinated C-fibres, the latter exhibiting slower conductance [12]. The $\mathrm{A} \delta$-fibre endings are located in the detrusor smooth muscle layer and are the most sensitive nerve endings in the bladder; accordingly, they are referred to as 'tension receptors' and are considered to be the primary mediators of the physiological sensation of bladder fullness. On the other hand, the nerve endings of the $\mathrm{C}$-fibres are found in the urothelium and lamina propria [13]. The C-fibres are thought to be only activated by distension that is greater than that required to activate A $\delta$-fibres and are considered to be less sensitive to contraction than to bladder distension. Factors which are considered to be important in pathology including high osmolality, high ambient $\mathrm{KCl}$ concentration or inflammation can activate a subgroup of $\mathrm{C}$-fibres. From these data it can be concluded that $\mathrm{C}$-fibres may primarily be involved in pathological situations and apparently are less important in the sensation of physiological bladder filling (except close to functional bladder capacity); these properties makes them a better candidate to be involved in the sensation of urgency. The non-neuronal release of neurotransmitters may also have a direct stimulatory effect on C-fibres [14, 15]. As they originate largely from the urothelium [16], the urothelium may play a specific role in generating urgency.
Several lines of evidence support the concept that urgency is a pathological sensation which is sensed by mechanisms which are at least partly distinct from those involved in sensing bladder filling. For example, some investigators have explored urgency by determining where the sensation is felt. In one study patients with painful bladder syndrome (PBS), OAB, stress urinary incontinence (SUI) and asymptomatic controls were asked to indicate the location of their urinary urge/urgency/discomfort on a body map [17]. Controls and SUI patients localised the urge to void to the suprapubic region only, whereas more than half of patients with PBS and a minority of those with $\mathrm{OAB}$ pointed to both suprapubic and vulval/urethral locations as the source of their urinary urgency/discomfort.

Functional position emission tomography studies have identified areas within the brain which are activated during storage and voiding, and these areas are underperfused in patients with DO [18]. Similar studies have identified that different areas of the cortex may be active during the perception of the physiological sensation of urge as compared to urgency [19] and there may be significant differences between those with 'good' as compared to 'bad' bladder control [20]. Some drugs such as opioid receptor agonists, gabapentin or GABA receptor ligands [21] and also muscarinic antagonists with good penetration into the brain such as oxybutynin [22] may exert beneficial effects on urgency by interfering with these central processing mechanisms.

\section{What causes non-voiding detrusor contractions and urgency?}

Non-voiding detrusor contractions could result from multiple causes. These include alterations at the level of the sensory signals originating in the afferent bladder nerves ('sensory urgency'). Equally possible are alterations at the level of the efferent nerve signals to the detrusor ("motor urgency'). Finally, an intrinsic malfunction of the smooth muscle is also possible (myogenic theory). Of note, these three possibilities are not necessarily mutually exclusive. The currently available evidence is insufficient to fully support one of these theories to the exclusion of any of the others and indeed it is likely that a different admixture of pathophysiology is present in different patients. In the following we will largely focus on the myogenic theory as this has been investigated in more detail than the other options and is also supported by circumstantial evidence from pressure-flow studies [23, 24].

Detrusor smooth muscle contractions can occur spontaneously or be evoked by paracrine factors and/or neurotransmitters. Physiological voiding appears largely driven by neurotransmitter-induced detrusor contractions. Human physiological bladder contractions are evoked by the 
neurotransmitter acetylcholine acting on muscarinic receptors, largely the $\mathrm{M}_{3}$ receptor [25]. Their coupling to contraction involves voltage-operated $\mathrm{Ca}^{++}$channels and rho kinase [26]. Paracrine mediators of detrusor contraction include non-neuronal acetylcholine [14] and ATP [27], the latter acting via ligand-gated ion channels. The relative contribution of non-neuronal stimuli, is physiologically low in humans as compared with other species [28] but can increase under pathological conditions [27, 29]. Alterations of cellular $\mathrm{Ca}^{++}$handling [30] and of rho kinase [31] may occur in disease and can contribute to alterations of muscle contractility by neuronal and paracrine agents. Spontaneous contractions play a smaller role in humans than in rodents, and it is not fully clear whether they are involved in the physiological resting tone of the bladder and/or DO, and/or are an epiphenomenon of in vitro conditions [32]. Micromotions may be an in vivo correlate of spontaneous contraction [33] and are more frequent in patients with sensory urgency [34].

Some pathologies leading to bladder dysfunction including DO and urgency may be associated with structural alterations of the bladder which can persist even after the causative insult is removed. For example, mural changes occur in the bladder wall associated with both ageing and bladder outlet obstruction (BOO), which include loss of detrusor muscle volume, decreased neuronal density, increased intramuscular fibrosis and increased excitability of detrusor muscle [35]. Moreover, BOO can be associated with repeated episodes of prolonged detrusor ischemia [36]. Some of these alterations as well as DO and urgency can persist after removal of obstruction both in animals [37] and patients [38].

\section{How do drugs affect non-voiding detrusor contractions and urgency?}

The current medical treatment of OAB largely rests on the use of muscarinic receptor antagonists [39, 40]. While the best way to assess urgency in $\mathrm{OAB}$ patients is still under debate $[41,42]$, several studies, largely based on counting urgency episodes, have demonstrated reductions of urgency using several muscarinic receptor antagonists including darifenacin [43, 44], fesoterodine [45-47], propiverine [48], solifenacin [48-52], tolterodine [46, 50, 53, 54] and trospium [55]. For some drugs beneficial effects on urgency have also been demonstrated using other means of assessment including several rating scales [44, 55-61]. Interestingly, several studies indicate that muscarinic receptor antagonist will reduce urgency episodes also in continent patients [62], indicating that they may genuinely have an action on urgency itself and not only produce a response that is secondary to reducing the number of incontinence episodes. However, it should not be ignored that such drugs did not significantly affect urgency in all studies [57, 63, 64]. Taken together these data demonstrate that muscarinic receptor antagonists as a class reduce the number of urgency episodes as well as urgency severity in $\mathrm{OAB}$ patients irrespective of the presence of incontinence and without major effects on physiological voiding.

Potential novel treatment of urgency, DO and/or OAB such as $\beta_{3}$-adrenoceptor agonists [65], vanilloids [66], botulinum toxin [67] as well as agents acting on the central nervous system [68], apparently make use of all of the above-mentioned mechanisms but their specific effects on urgency largely remain to be established, particularly in direct comparison with muscarinic receptor antagonists.

\section{Conclusions}

Urgency is a pathological sensation which differs at least partly from the physiological urge to void upon bladder filling. Mechanisms involved in urgency are not necessarily the same as those involved in DO or in other OAB symptoms such as frequency, nocturia and urgency incontinence. Specifically, uncertainty concerning the validity of DO as a surrogate marker of urgency is a stumbling block for further research in this area. While muscarinic receptor antagonists have some efficacy against urgency, a better understanding of the underlying pathophysiology is likely to help the development of more effective treatments for this bothersome symptom.

Acknowledgments Outside this manuscript, Christopher R. Chapple has received funding from Astellas, Pfizer, Novartis, Allergan and Recordati and Martin C. Michel from Astellas, Bayer, Boehringer and Pfizer. Work by the authors has also been supported through Coordination Theme 1 (Health) of the European Community's FP7, Grant agreement number HEALTH-F2-2008-223234.

Conflict of interest statement The idea for writing this manuscript arose from a meeting sponsored by Astellas but the manuscript was written completely independent from this or other companies.

Open Access This article is distributed under the terms of the Creative Commons Attribution Noncommercial License which permits any noncommercial use, distribution, and reproduction in any medium, provided the original author(s) and source are credited.

\section{References}

1. Abrams P, Cardozo L, Fall M et al (2002) The standardisation of terminology of lower urinary tract function: report from the Standardisation Sub-committee of the International Continence Society. Neurourol Urodyn 21:167-178

2. Michel MC, Chapple CR (2009) Basic mechanisms of urgency: basic and clinical evidence. Eur Urol. doi:10.1016/j.eururo. 2009.05.028 
3. Oliver S, Fowler C, Mundy A et al (2003) Measuring the sensation of urge and bladder filling during cystometry in urge incontinence and the effect of neuromodulation. Neurourol Urodyn 22:7-16

4. Lowenstein L, Fitzgerald MP, Kenton K et al (2008) Validation of a real-time urodynamic measure of urinary sensation. Am J Obstet Gynecol 198:661.e1-661.e5

5. Wyndaele J-J, van Meel TD, de Wachter S (2004) Detrusor overactivity. Does it represent a difference if patients feel the involuntary contractions? J Urol 172:1915-1918

6. Malone-Lee J, Henshaw DJE, Cummings K (2003) Urodynamic verification of an overactive bladder is not a prerequisite for antimuscarinic treatment response. BJU Int 92:415-417

7. Rovner E, Payne C, Yalla S et al (2005) Response to fesoterodine in overactive bladder $(\mathrm{OAB})$ patients is independent of the uryodynamic finding of detrusor overactivity. https://www. icsoffice.org/publications/2005/PDF/0147.PDF

8. Matharu G, Donaldson MMK, McGrother CW et al (2005) Relationship between urinary symptoms reported in a postal questionnaire and urodynamic diagnosis. Neurourol Urodyn 24:100-105

9. Hashim H, Abrams P (2006) Is the bladder a reliable witness for predicting detrusor overactivity? J Urol 175:191-195

10. Haylen BT, Chetty N, Logan V et al (2007) Is sensory urgency part of the same spectrum of bladder dysfunction as detrusor overactivity? Int Urogynecol J 18:123-128

11. de Wachter S, van Meel TD, Wyndaele J-J (2008) Can a faked cystometry deceive patients in their perception of filling sensations? A study on the reliability of spontaneous reported cystometric filling sensations in patients with non-neurogenic lower urinary tract dysfunction. Neurourol Urodyn 27:395-398

12. Morrison J, Birder LA, Craggs M et al (2006) Neural control. Plymbridge Distributors Ltd, Plymouth, pp 363-422

13. Morrison J (1999) The activation of bladder wall afferent nerves. Exp Physiol 84:131-136

14. Lips KS, Wunsch J, Sarghooni S et al (2007) Acetylcholine and molecular components of its synthesis and release machinery in the urothelium. Eur Urol 51:1042-1053

15. Yoshida M, Masunaga K, Satoji Y et al (2008) Basic and clinical aspects of non-neuronal acetylcholine: expression of non-neuronal acetylcholine in urothelium and its clinical significance. J Pharmacol Sci 106:193-198

16. Yoshimura N, Kaiho Y, Miyazato M et al (2008) Therapeutic targets for lower urinary tract dysfunction. Naunyn Schmiedebergs Arch Pharmacol 377:437-448

17. Fitzgerald MP, Kenton KS, Brubaker L (2005) Localization of the urge to void in patients with painful bladder syndrome. Neurourol Urodyn 24:633-637

18. Bulmer P, Abrams P (2004) The unstable detrusor. Urol Int 72:1-12

19. Athwal BS, Berkley KJ, Hussain I et al (2001) Brain responses to changes in bladder volume and urge to void in healthy men. Brain 124:369-377

20. Griffiths D, Tadic SD (2008) Bladder control, urgency, and urge incontinence: evidence from functional brain imaging. Neurourol Urodyn 27:466-474

21. Andersson K-E (2004) New pharmacological targets for the treatment of the overactive bladder: an update. Urology 63(Suppl 3A):32-41

22. Kono M, Nakamura Y, Ishiura Y et al (2006) Central muscarinic receptor subtypes regulating voiding in rats. J Urol 175:353-357

23. Cucchi A, Quaglini S, Siracusano S et al (2006) Urgency degree and bladder contraction velocity: sequential changes in women with idiopathic detrusor overactivity. Neurourol Urodyn 25:123127

24. Cucchi A, Quaglini S, Rovereto B (2007) Relationships between micturition urgency and involuntary voiding dynamics in men with urinary incontinence from idiopathic detrusor overactivity. J Urol 178:563-567

25. Schneider T, Fetscher C, Krege S et al (2004) Signal transduction underlying carbachol-induced contraction of human urinary bladder. J Pharmacol Exp Ther 309:1148-1153

26. Frazier EP, Peters SLM, Braverman AS et al (2008) Signal transduction underlying control of urinary bladder smooth muscle tone by muscarinic receptors and $\beta$-adrenoceptors. Naunyn Schmiedebergs Arch Pharmacol 377:449-462

27. Rapp DE, Lyon MB, Bales GT et al (2005) A role for the P2X receptor in urinary tract physiology and in the pathophysiology of urinary dysfunction. Eur Urol 48:303-308

28. Sibley GN (1984) A comparison of spontaneous and nervemediated activity in bladder muscle from man, pig and rabbit. J Physiol (Lond) 354:431-443

29. Fry $\mathrm{CH}$, Wu C, Mundy AR (1999) Bladder instability and detrusor smooth muscle function. Exp Physiol 84:161-169

30. Fry CH, Skennerton D, Wood D et al (2002) The cellular basis of contraction in human detrusor smooth muscle from patients with stable and unstable bladders. Urology 59(Suppl 5A):3-12

31. Peters SLM, Schmidt M, Michel MC (2006) Rho kinase: a target for treating urinary bladder dysfunction? Trends Pharmacol Sci 27:492-497

32. Fry CH (2004) Experimental models to study the physiology, pathophysiology and pharmacology of the lower urinary tract. J Pharmacol Toxicol Methods 49:201-210

33. Coolsaet BL, van Duyl WA, van Os-Bossagh P et al (1993) New concepts in relation to urge and detrusor overactivity. Neurourol Urodyn 12:463-471

34. Drake MJ, Harvey IJ, Gillespie JI et al (2005) Localized contractions in the normal human bladder and in urinary urgency. BJU Int 95:1002-1005

35. Elbadawi A, Meyer S (1989) Morphometry of the obstructed detrusor. I. Review of the issues. Neurourol Urodyn 8:163-171

36. Greenland JE, Brading AF (2001) The effect of bladder outflow obstruction on detrusor blood flow changes during the voiding cycle in conscious pigs. J Urol 165:245-248

37. Michel MC, Barendrecht MM (2008) Physiological and pathological regulation of the autonomic control of urinary bladder contractility. Pharmacol Ther 117:297-312

38. Abrams PH, Farrar DJ, Turner-Warwick RT et al (1979) The results of prostatectomy: a symptomatic and urodynamic analysis in 152 patients. J Urol 121:640-642

39. Chapple CR, Khullar V, Gabriel Z et al (2008) The effects of antimuscarinic treatments in overactive bladder: an update of a systematic review and meta-analysis. Eur Urol 54:543-562

40. Novara G, Galfano A, Secco S et al (2008) A systematic review and meta-analysis of randomized controlled trials with antimuscarinic drugs for overactive bladder. Eur Urol 54:740-764

41. Michel MC, Oelke M, Goepel M et al (2007) Relationships among symptoms, bother, and treatment satisfaction in overactive bladder patients. Neurourol Urodyn 26:190-195

42. Starkman JS, Dmochowski RR (2008) Urgency assessment in the evaluation of overactive bladder (OAB). Neurourol Urodyn 27:13-21

43. Haab F, Stewart L, Dwyer P (2004) Darifenacin, an $\mathrm{M}_{3}$ selective receptor antagonist, is an effective and well-tolerated once-daily treatment for overactive bladder. Eur Urol 45:420-429

44. Steers WD, Corcos J, Foote J et al (2005) An investigation of dose titration with darifenacin, an $\mathrm{M}_{3}$-selective receptor antagonist. BJU Int 95:580-586

45. Khullar V, Rovner ES, Dmochowski R et al (2008) Fesoterodine dose response in subjects with overactive bladder syndrome. Urology 71:839-843

46. Chapple C, van Kerrebroeck P, Tubaro A et al (2007) Clinical efficacy, safety and tolerability of once-daily fesoterodine in subjects with overactive bladder. Eur Urol 52:1204-1212 
47. Nitti VW, Dmochowski R, Sand PK et al (2007) Efficacy, safety and tolerability of fesoterodine for overactive bladder syndrome. J Urol 178:2488-2494

48. Yamaguchi O, Marui E, Kakizaki H et al (2007) Randomized, double-blind, placebo- and propiverine-controlled trial of the once-daily antimuscarinic agent solifenacin in Japanese patients with overactive bladder. BJU Int 100:579-587

49. Chapple CR, Arano P, Bosch JLHR et al (2004) Solifenacin appears effective and well tolerated in patients with symptomatic idiopathic detrusor overactivity in a placebo- and tolterodinecontrolled phase 2 dose-finding study. BJU Int 93:71-77

50. Chapple CR, Rechberger T, Al-Shukri S et al (2004) Randomized, double-blind placebo- and tolterodine-controlled trial of the once-daily antimuscarinic agent solifenacin in patients with symptomatic overactive bladder. BJU Int 93:303-310

51. Cardozo L, Lisec M, Millard R et al (2004) Randomized, doubleblind placebo-controlled trial of the once-daily antimuscarinic agent solifenacin succinate in patients with overactive bladder. J Urol 172:1919-1924

52. Gittelman MC (2003) The efficacy and safety of solifenacin in adults with overactive bladder: a multicenter, placebo-controlled study. Int J Gynaecol Obstet 83(Suppl 3):94

53. Kaplan SA, Roehrborn CG, Dmochowski R et al (2006) Tolterodine extended release improves overactive bladder symptoms in men with overactive bladder and nocturia. Urology 68:328332

54. Khullar V, Hill S, Laval K-U et al (2004) Treatment of urgepredominant mixed urinary incontinence with tolterodine extended release: a randomized, placebo-controlled trial. Urology 64:269-275

55. Zinner N, Gittelman M, Harris R et al (2004) Trospium chloride improves overactive bladder symptoms: a multicenter phase III trial. J Urol 171:2311-2315

56. Freeman R, Hill S, Millard R et al (2003) Reduced perception of urgency in treatment of overactive bladder with extended-release tolterodine. Obstet Gynecol 102:605-611

57. Cardozo L, Dixon A (2005) Increased warning time with darifenacin: a new concept in the management of urinary urgency. J Urol 173:1214-1218
58. Cardozo L, Coyne KS, Versi E (2005) Validation of the urgency perception scale. BJU Int 95:591-596

59. Zinner N, Harnett M, Sabounjian L et al (2005) The overactive bladder-symptom composite score: a composite symptom score of toilet voids, urgency severity and urge urinary incontinence in patients with overactive bladder. J Urol 173:1639-1643

60. Dmochowski R, Abrams P, Marschall-Kehrel D et al (2007) Efficacy and tolerability of tolterodine extended release in male and female patients with overactive bladder. Eur Urol 51:10541064

61. Nitti VW, Dmochowski R, Appell RA et al (2006) Efficacy and tolerability of tolterodine extended-release in continent patients with overactive bladder and nocturia. BJU Int 97:1262-1266

62. Michel MC, de la Rosette JJMCH, Piro M et al (2005) Comparison of symptom severity and treatment response in patients with incontinent and continent overactive bladder. Eur Urol 48:110-115

63. Madersbacher H, Halaska M, Voigt R et al (1999) A placebocontrolled, multicentre study comparing the tolerability and efficacy of propiverine and oxybutynin in patients with urgency and urge incontinence. BJU Int 84:646-651

64. Robinson D, Cardozo L, Terpstra G et al (2007) A randomized double-blind placebo-controlled multicentre study to explore the efficacy and safety of tamsulosin and tolterodine in women with overactive bladder syndrome. BJU Int 100:840-845

65. Chapple CR, Yamaguchi O, Ridder A et al (2008) Clinical proof of concept study (Blossom) shows novel $\beta 3$ adrenoceptor agonist YM178 is effective and well tolerated in the treatment of symptoms of overactive bladder. Eur Urol (Suppl 7):239

66. Avelino A, Cruz F (2006) TRPV1 (vanilloid receptor) in the urinary tract: expression, function and clinical applications. Naunyn Schmiedebergs Arch Pharmacol 373:287-299

67. Karsenty G, Denys P, Amarenco G et al (2008) Botulinum toxin A $\left(\right.$ Botox $\left.{ }^{\circledR}\right)$ intradetrusor injections in adults with neurogenic detrusor overactivity/neurogenic overactive bladder: a systematic literature review. Eur Urol 53:275-287

68. Andersson K-E (2007) LUTS treatment: future treatment options. Neurourol Urodyn 26:934-947 